\title{
The Impact of Social Network Sites on Students' Psychological Problems
}

\author{
https://doi.org/10.3991/ijet.v16i09.20799 \\ Elda Tartari ${ }^{(凶)}$, Lindita Lutaj \\ University of Aleksandër Moisiu, Durrës, Albania \\ eldatartariegmail.com
}

\begin{abstract}
Students in recent years spend a considerable amount of time on social networking websites. They have made online access and navigation through these sites part of their daily activities. The impact of social network sites in particular has become a major subject of discussion among various studies, because some of them see these pages as a threat or obstacle, while the rest argue that them affects positively the age of adolescence. A quantitative, descriptive and exploratory survey was conducted to identify the impact of this involvement on adolescents' behaviour that affect their psychological development. The research sample consisted of 893 students, between the ages 10-15 years old, users of the social network sites. This champion has been taken from middle school institutions from different cities of Albania. The study confirmed that students are using social network sites for a long period of time during the day. They have become addicted to these online networks and they already display some behavior patterns. As a conclusion, the study found that the inclusion in social network sites, if students spend a considerable amount of time on them, has a negative impact in their psychological problems. Parents, teachers and students need to communicate with each other in order to identify and avoid the risks of social network sites and also other studies should be done in this field and suggest different strategies to manage the psychological problems caused by the use of social networking sites.
\end{abstract}

Keywords — Students, social network sites, psychological problems, impact

\section{Introduction}

Social media, through its interactive platform, enables users to communicate with each other members in order to establish social relationships, and share information and knowledge in relation to experiences and activities in real life. Teenagers spend a large amount of their time interacting online in social life. The use of social networks by adolescents occurs simultaneously with their emerging identity, their developing sexuality as well as their physical and moral development. The impact of social media and social networks in particular has become a major subject of discussion among scholars, because some of them see it as a threat or obstacle, while the rest argue that it affects positively this transition period. Social media can provide adolescents a 
supportive environment to explore romance, friendship, and social status as well as give them an opportunity to share and discuss their musical tastes, information about television and movies, video and online games, as well as other aspects of adolescent culture [1]. In the psychology of development, Erikson (1968) proposed a theory known as "Erikson's Eight Life-Span Stages", according to which development takes place throughout the whole life [2]. In each of the eight stages the individual experiences a crisis, and this is faced successfully, he or she passes to the next stage. The fifth stage of development refers to 10 to 20 years old adolescence (Identity versus Identity Confusion). At this stage, adolescents have the opportunity to explore new roles, an increased level of responsibility to build a sense of personal identity. Adolescents also experience a war and confusion around themselves to determine what they are and adapt themselves to the world. In this period, the individual undergoes major biological, psychological and social changes.

\section{$2 \quad$ Literature Review}

Nowadays social networking sites (SNSs) have embarked on people's daily lives at an amazing speed as an important social platform to mediate communication [3]. Because of the growing popularity of SNSs, personal and social interactions with friends, family, and professional contacts have transformed themselves from the offline sphere into an online subject (individual of the virtual world) [4]. SNSs and especially Facebook have not only attracted the attention of teenagers, but they have become also an active component of their daily lives, interactions and social engagements [5]. This virtual space has also created numerous cyber scenarios that have become the bases for the virtual relationships that have arisen in diverse and numerous social networks [6]. Using social networks creates opportunities for emotional anxieties caused by threats, teasing or humiliating elements. This is a common risk for all adolescents and preadolescents. Current data suggest that online harassment is not as common as offline harassment [7] but it can happen to any person newly online, and it may result in profound psycho-social outcomes including depression, anxiety, severe isolation and suicide [8]. While other studies point out that the intensity of the online world is thought to be a factor that may cause depression in some teenagers. As with offline depression, preadolescents and adolescents suffering from Facebook depression are at risk of social isolation, aggressiveness, substances promotion, and insecure sexual practices [9]. Relying on a study conducted by the Association of American Psychologists [10], teenagers using the social network Facebook often exhibit narcissistic tendencies, while young people having a large Facebook presence exhibit many signs of other psychological disorders such as antisocial behavior, mania and aggression tendency. Also, Rideout [11] argues in his study that adolescents standing for a long time in social media are more likely to get into trouble and are often sad, disgruntled, and upset whiles Abbas et al., [12] claim that the excessive use of social media makes students emotionally and physically imbalanced and results in dull or irritable behavior. Another factor related to the 'forms of social relationship' characteristic of adolescents associated with playful themes. Under this label adoles- 
cents includes verbal aggressions such as insults, spreading false rumours, or visual abuse such as the publication and dissemination of images or videos [13]

According to Kim [14] spending more time on the computer is negatively related to mental health in the following year. Also, the use of digitals tools has a direct influence on memorization as a learning process and it seems negative when this duration of use exceeds 2 hours [15]. The research questions that help fulfil the purpose of the study are:

- What is the role of the social network sites on the psychological problems of students aged 10-15 years?

- Are the children of this age group dependent from social network sites?

- Do parents and teachers inform about the risks that these social network sites offer?

\section{Methodology}

To accomplish the purpose of this study, the method of quantity based on the interpretive paradigm was used, as it describes and analyses the impact of social network sites on the psychological problems among students aged 10-15 years. Various national and international studies define those belonging to this age as children, but also as adolescents [16], [17], [18]. We should bear in mind that when using in this study the terms child and adolescent, we will refer to the students of this age. The sample of this study is 893 students taken from 11 primary schools in five different cities of Albania that were randomly selected, but provided that they were users of social networks. During the collection of information, several ethical principles were taken into account, which helped to avoid misinterpretation as the subjects were to express their personal attitude. The survey created for this study gathered the demographic information of the students involved in the study and, with the help of questions drawn up on the Likert scale, the frequency of the phenomenon was studied (Never, rarely, sometimes, often, too often). The measuring instrument was coded to facilitate the data registering and the analysis process. Once the data collection was completed, they were analysed using the IBM SPSS version 16.0 statistical package and the data were interpreted based on the descriptive analysis.

\section{Data Analysis}

The overall study sample is 893 students out of which 339 are female and 554 male. With regard to the sample distribution by dwelling in relation to the involvement in different social sites, from the city of Tirana were taken 428 , from the city of Shkodra 105, from the city of Vlora 140 , from the city of Durres 154 , and from the city of Korça 66 students. The surveyed were asked about the person who created their online addresses and the results show that $7.8 \%$ of them were asisted by the parents. $12.8 \%$ of them were asissted by the brodher or sister. $59.4 \%$ of them said that they accessed personally to online addresses, $11.8 \%$ were asisted by other relatives while $7.8 \%$ were asisted by friends. 
The students participating in the study were asked if their parents and teachers were engaged in advising this age group related to the risks coming from the social media. The analysis of the results shows that $75.1 \%(\mathrm{~N}=657)$ of the surveyed confirms that parents are communicating with them while $24.9 \%(\mathrm{~N}=218)$ declared that parents do not communicate to them on this subject. As we could see from the correlation on the table 6 related to the parents' communication with their children is statistically significat. The percentage of the students advised by their parents is nearly the same in all cities.

Table 1. Percentage of parents communicating with their children about the risks offered by SNSs by place of residence.

\begin{tabular}{|c|l|c|c|c|c|c|c|}
\hline \multirow{2}{*}{\begin{tabular}{c} 
Parent-child com- \\
munication about \\
social networking \\
\multirow{2}{*}{\begin{tabular}{c} 
risks. \\
\cline { 2 - 8 }
\end{tabular}}
\end{tabular}} & Yes & $77.4 \%$ & $63.7 \%$ & $75.2 \%$ & $79.1 \%$ & $64.9 \%$ & $\mathbf{7 4 . 9 \%}$ \\
\cline { 2 - 8 } & No & $22.6 \%$ & $36.3 \%$ & $24.8 \%$ & $20.9 \%$ & $35.1 \%$ & $\mathbf{2 5 . 1 \%}$ \\
\cline { 2 - 8 } & Total & $\mathbf{1 0 0 \%}$ & $\mathbf{1 0 0 \%}$ & $\mathbf{1 0 0 \%}$ & $\mathbf{1 0 0 \%}$ & $\mathbf{1 0 0 \%}$ & $\mathbf{1 0 0 \%}$ \\
\hline
\end{tabular}

Chi-Square $=12.5 ; \mathrm{p}<0.05$

Beside this, $63.5 \%$ of the respondents stated to have been informed by the teachers about the possible dangers of social networks, while $36.5 \%$ of the respondents stated that teachers did not inform them. Thus, most of parents and teachers advise children about the potential dangers that social networks may cause.

Students who have online addresses stated that they access them daily (66\%), weekly $(24.7 \%)$ and monthly $(9.3 \%)$. So, most of them visit their addresses every day. This means that students have made access to their online profiles part of their daily activities. To identify whether there are differences between age and frequency on the social networks, these questions were correlated with each other and it turned out that they have a statistically significant relationship $(\mathrm{p}=0.00)$ which means that with age we have greater involvement of students for access their address every day. This is clearly seen in the table below where students aged 15, 14 and 13 have a high density of access to their address.

Table 2. Correlation of the frequency of access to the address in the social network Facebook by students according to their age.

\begin{tabular}{|l|c|c|c|c|c|c|c|}
\hline $\begin{array}{c}\text { How often do you } \\
\text { visit your ad- } \\
\text { dress? }\end{array}$ & \multicolumn{6}{|c|}{ Age } & \multirow{2}{*}{ Total } \\
\cline { 2 - 8 } & $\mathbf{1 0}$ years old & $\mathbf{1 1}$ y.o. & $\mathbf{1 2}$ y.o. & $\mathbf{1 3}$ y.o. & $\mathbf{1 4}$ y.o. & $\mathbf{1 5}$ y.o. & \\
\hline Every day & 30 & 53 & 65 & 122 & 144 & 154 & $\mathbf{5 6 8}$ \\
\hline Every week & 29 & 29 & 45 & 36 & 48 & 28 & $\mathbf{2 1 5}$ \\
\hline Every month & 13 & 16 & 14 & 14 & 14 & 9 & $\mathbf{8 0}$ \\
\hline Total & $\mathbf{7 2}$ & $\mathbf{9 8}$ & $\mathbf{1 2 4}$ & $\mathbf{1 7 2}$ & $\mathbf{2 0 6}$ & $\mathbf{1 9 1}$ & $\mathbf{8 6 3}$ \\
\hline
\end{tabular}

Chi-Square $=60.5 ; \mathrm{p}=0.00$

Below is the percentage of students who access their account during the day. Of which 278 students answered that thay usually access once a day, 299 students access two to three times a day, 101 students access four to five times a day and 196 students 
access more than 6 times a day. As seen in the figure below most students access two to three times a day their online addresses.

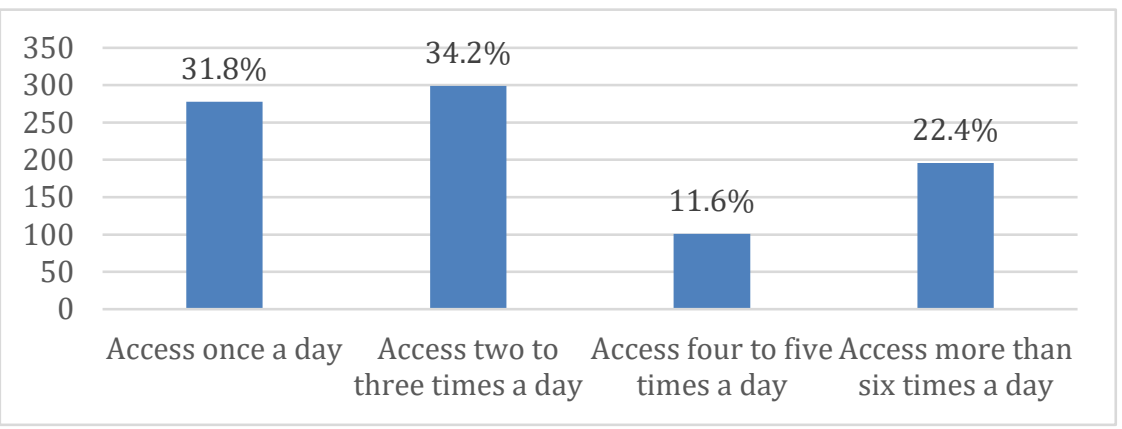

Fig. 1. Accessing the online addresses during the day.

To have a clear picture if there is any difference between the frequency of address during the day on the social network and the age of the respondents, a correlation was made between them which showed according to Pearson Chi-Square a statistically significant relationship $(\mathrm{p}=0.00)$. This means that with increasing age we have an increase in the frequency of access to addresses during the day. This is mainly noticed in the response more than 6 times where we have a gradual increase in the frequency of visiting online sites during the day with increasing age.

Respondents were also asked about the time when they access during the day. They stated that 26 students (3\%) access their address in the morning, 137 respondents $(15.8 \%)$ access during lunch time, 421 respondents $(48.5 \%)$ access in the afternoon, 206 respondents $(23.7 \%)$ access during dinner hours and 78 respondents $(9 \%)$ access in the late hours of the night. According to this analysis we notice that most students enter during the afternoon hours. It is interesting that a considerable part access during evening hours thus avoiding family members and paying attention to staying in their account, while we have a percentage $(9 \%)$ which we should worry about because they stay at the address of them during the late hours of the night. This kind of attitude during these hours physically and psychologically harms these children.

\subsection{Sleep shifting}

To better understand the impact of this phenomenon faced by today's children, the respondents were asked whether their social network sites affected their sleeping late at night. The respondents' answers are shown in the figure below. 


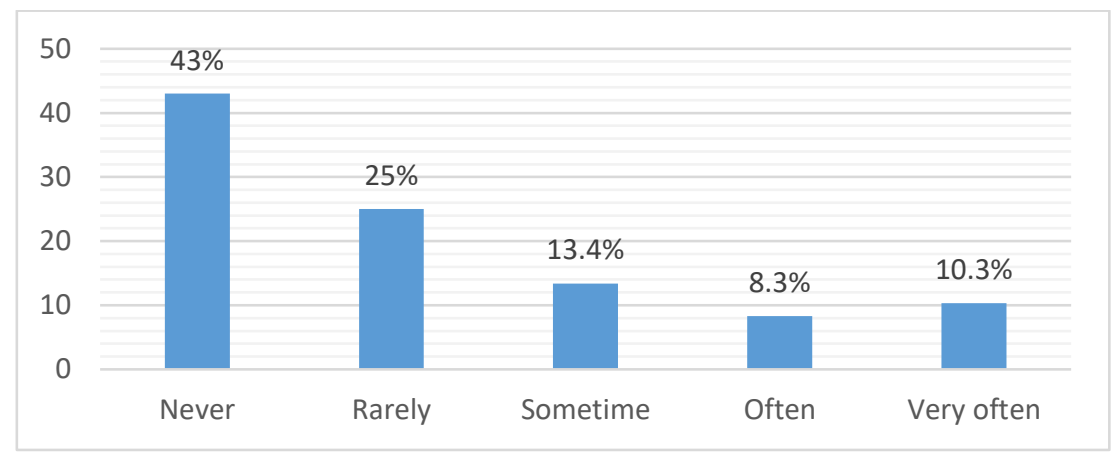

Fig. 2. Influence of SNSs in sleep shifting

This question was answered by 880 children who are SNSs users, of whom $43 \%$ or 378 respondents responded that they never shifted the sleep due to SNSs, and $57 \%$ or 502 respondents affirmed that their sleep had been shifted because of SNSs, among which $25 \%$ of them or 220 children said to have done this rarely, $13.4 \%$ or 118 children several times, $8.3 \%$ or 73 children often and $10.3 \%$ or 91 children very often. As we have observed, there is a high percentage of children shifting sleep often and very often due to their staying awake in their address on social network sites. The lack of sleep causes major problems in physical and psychological development not only among children of this age group who are in a development process, but also in the adult age groups.

The table below shows the distribution of students by age in relation to sleep shifting due to staying on SNSs. These differences in distribution are statistically significant. The tendency to stay awake in the late hours of the night is mainly remarked among the students aged 15 years, followed at a slightly lower level by 14 and less than 13 years old. The students shifting their sleep at the age of 12-13 are a few. And it's an interesting fact that we also have 10-years-old students shifting their sleep because of staying at their address.

Table 3. Distribution of students by age in relation to sleep shifting due to stay on social network sites

\begin{tabular}{|l|c|c|c|c|c|c|}
\hline \multirow{2}{*}{ Age } & \multicolumn{5}{|c|}{ Does it occur to you to sleep late due to staying in SNSs? } & \multirow{2}{*}{ Total } \\
\cline { 2 - 6 } & Never & Rarely & Sometimes & Often & Very often & \\
\hline 10 years & 47 & 17 & 6 & 6 & 1 & 77 \\
\hline 11 years & 60 & 24 & 10 & 2 & 3 & 99 \\
\hline 12 years & 65 & 32 & 15 & 4 & 8 & 124 \\
\hline 13 years & 79 & 43 & 23 & 13 & 15 & 173 \\
\hline 14 years & 80 & 57 & 29 & 19 & 25 & 210 \\
\hline 15 years & 44 & 46 & 35 & 28 & 38 & 191 \\
\hline Total & 375 & 219 & 118 & 72 & 90 & 874 \\
\hline
\end{tabular}

Chi-Square=90.9; $\mathrm{p}=0.000$ 


\subsection{Concern shown by members surrounding the child about the time of his staying on SNSs}

To understand the sense of addiction caused by SNSs, students who are users of this network were asked whether others (parents, sister, brother, friend) complain about the time they spend on SNSs. Out of their answers, it was noted that $53.9 \%$ or 471 of them claimed that others never complain about their stay on SNSs, while $46.1 \%$ or 401 said that others complain about the time they spend on this social network, of which $21.9 \%$ say that others complain rarely, $12.2 \%$ claimed that others complain several times, $7.1 \%$ often and $5 \%$ very often. If we group the categories "often" and "very often", we remark that they are about $12.1 \%$ or 106 students who are thinking that they are heavily dependent on SNSs as people around them complain about the time they are present in their accounts.

\subsection{The feeling created against restriction on the social network sites}

The respondents were also asked whether they felt restless, in a bad mood or nervous when their social networking were restricted. This question was answered by 871 users. $62.8 \%$ or 547 children answered that they did not feel like that at all, while $37.2 \%$ or 322 children felt restless, nervous or in a bad mood when their stay in SNSs was restricted. Of the children feeling distressed, nervous or in a bad mood, $28.6 \%$ or 249 said they felt as such a little, while $5.7 \%$ or 75 children felt this very much. As it can be seen in the above analysis, a considerable part of children react psychologically to the restriction made to their time in this social network.

\subsection{Communication with known and unknown people}

Respondents included in the study were asked if they communicate through social networks with known and unknown people as shown in Figure 2. The question "Do you communicate with familiar people?" that is represented in the graph in blue colour, $45.5 \%$ or 383 students responded with "very often", $24.2 \%$ or 201 students with "often", $11.6 \%$ or 98 students with "several times", $7.7 \%$ or 64 students with "rarely" and $11.2 \%$ with "never". Meanwhile in the red colour is represented the question "Do you communicate with unknown people?" Among these, $64.9 \%$ or 548 students are responded that they have never communicated with unknown people, while $35.1 \%$ or 316 students have communicated with unknown persons. Referring to this figure, the survey confirms that most students use online social networks to communicate with known people but it was also noted that a significant part of students $(35.1 \%)$ communicate with unknown persons. This type of communication exposes them to various risks which can affect and cause psychological problems in these adolescents. 


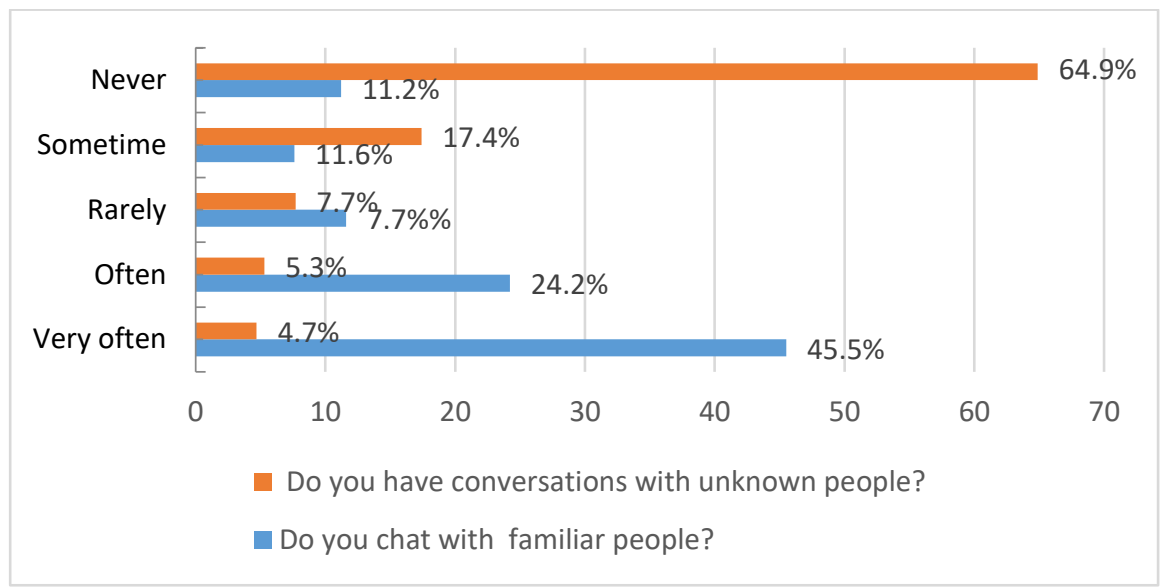

Fig. 3. Comparison of the percentage of students' communication with known and unknown people

Table 2 shows the percentages of students by gender in relation to conversations with unknown people. These gender differences are statistically significant. In total, we have 846 students, out of whom 322 are girls and 231 of them never communicate with unknown people, while the rest $(28.3 \%)$ does communicate. 524 are boys, of whom $60.1 \%$ never communicate with the unknown people, while the rest $(39.9 \%)$ does communicate. Based on this percentage, we noted that boys communicate with the unknown persons more than girls.

Table 4. Percentage of students using SNSs by gender, in relation to their communication with strangers

\begin{tabular}{|l|c|c|c|c|c|c|c|c|c|c|c|c|}
\hline \multirow{2}{*}{ Gender } & \multicolumn{9}{|c|}{ Do you communicate with unknown peoples? } & \multicolumn{2}{|c|}{ Total } \\
\cline { 2 - 12 } & Very often & \multicolumn{2}{|c|}{ Often } & $\begin{array}{c}\text { Several } \\
\text { times }\end{array}$ & \multicolumn{2}{c|}{ Rarely } & \multicolumn{2}{|c|}{ Never } & \multicolumn{2}{|c|}{} \\
\hline Female & 15 & $4.6 \%$ & 10 & $3.1 \%$ & 22 & $6.8 \%$ & 44 & $13.6 \%$ & 231 & $71.7 \%$ & 322 & $38.1 \%$ \\
\hline Male & 25 & $6.7 \%$ & 35 & $6.6 \%$ & 44 & $8.3 \%$ & 103 & $19.6 \%$ & 317 & $60.1 \%$ & 524 & $61.9 \%$ \\
\hline
\end{tabular}

Chi-Square $=13.4 ; \mathrm{p}=0.009$

\section{$5 \quad$ Discussions}

In order to perceive the sense of addiction caused by SNSs, students were asked whether others (parents, siblings, brother, mate, wife) complain about the time they spend on social network sites, and $46.1 \%$ or 401 students claimed that the people around them complain about their staying online. A cause for concern is constituted by the students saying that others complain "often" and "very often". Their number reaches about $12.1 \%$ or 106 students. This shows that these students are addicted to SNSs, as people around them complain about their behaviour. Addiction to this network causes problems to children and it has already been concluded that the long time 
engagement in the social networks can have adverse effects on children's mental and physical health through cyber bullying (outrage through messages or pictures) or lack of physical activity [19]. This concern is also supported by Davila et al. [20], who argues that teenagers and adolescents spending a lot of their time on social networking sites like Facebook (FB), are caught in depression by Facebook, which is associated with the classic signs of depression, and the American Psychological Association claims that long-standing presence in FB causes the emergence of many psychological disorders such as antisocial behaviour, mania tendency and aggression.

Students affected by the addiction phenomenon, in cases when their usage of social networks is restricted (generally by parents), feel disturbed, nervous and in a bad mood. The study found that $37.2 \%$ of children aged $10-15$ years feel such psychological changes if their staying on FB gets restricted, with $28.6 \%$ of the respondents feeling it "a little" and 5.7\% feeling it "very much". Communicating with strangers is another factor affecting the psychological development of children of this age group. Looking at the survey conducted by World Vision Albania and Kosovo [21] for children of the ages 13 to 18 in Albania, it was found that $47 \%$ of the interviewed children, within the last year, admit to have been contacted online by an unknown individual, while $33.2 \%$ of the children surveyed in the age group 10-15 years claim to communicate with strangers. This percentage is slightly higher than that of children in the European Union (32\%) in 2010 relying on Livingstone et al., [16].

The study found that boys communicate more with strangers than girls. The children that keep in touch with strangers are at risk of emotional anxieties caused by threats, teasing or humiliation. According to Hindu S. Patchin JW [8] this type of communication can cause deep psycho-social consequences including depression, anxiety, severe isolation, and suicide. These children are also vulnerable to sexual harassment including a wide variety of behaviours that can be transmitted by the sender through unwanted admonition and sexual assault. Communication with strangers favours these risks more than communication with known people. More than half $(57 \%)$ of the respondents say that their sleep to have been shifted due to their activity on SNSs, and we should pay more attention especially to $8.3 \%(\mathrm{~N}=73)$ of the children having experienced this "often", and to $10.3 \%(\mathrm{~N}=91)$ of the children having experienced this "very often", because the lack of sleep causes serious problems to their physical and psychological development by creating great psychological and psychological disorders not only among the children of this group, already in growth process, but also in the adult age groups. The tendency to stay late at night is mainly remarked among the 15-year-old students, followed at a slightly lower rate by 14 year-olds and fewer among the 13-year-olds. Of a small number are also the 12-13 year-olds displacing their sleep due to SNSs, and it is interesting the fact that we have 10 -year-old students shifting their sleep due to the stay at their address.

\section{Conclusion}

Adolescents spend a considerable amount of time on social networking sites. Online activities of this age group for a long time create psychological problems such 
as dependence on these networks, sleep problems by shortening his hours and constant communication with unknown persons which exposes them to various dangers offered by online communities. All these problems created in adolescence leave traces and affect their psychological development. Although teachers and parents have informed students and their children about the problems posed by staying on social media, there is still a need for more frequent and continuous communication. Parents mainly need to keep their children under constant surveillance by managing their use of technology and time spent online in order to prevent the various psychological problems created by addiction to social media. Also, other studies still need to be developed in this field to better understand the impact that social networks have on the psychological development of children and to suggest different strategies to manage the psychological problems caused by the use of social networks in this age.

\section{$7 \quad$ References}

[1] Ito, M., Horst, H. A., Bittanti, M., Stephenson, B. H., Lange, P. G., Pascoe, C. J., \& Martínez, K. Z. (2009). Living and learning with new media: Summary of findings from the digital youth project: Cambridge, MA: MIT Press. https://doi.org/10.7551/mitpre ss/8519.001.0001

[2] Erikson, E. H. (1946). "Ego development and historical change.," The Psychoanalytic Study of the Child, 2(1), p. 359-396.

[3] Correa, T., Hinsley, A. W., \& de Zuniga, H. G. (2010). "Who interacts on the web? The intersection of users' personality and social media use," Computers in Human Behavior, 26(1),, pp. 247-253. https://doi.org/10.1016/j.chb.2009.09.003

[4] Gallion, A. (2010). "Applying the Uses and Gratifications Theory to Social Networking Sites: A Review of Related Literature," [Online]. Available: https://www.academia.edu/ 1077670/Applying the_Uses_and_Gratifications_Theory_to_Social_Networking_Sites_A _Review_of_Related_Literature. https://doi.org/10.31274/etd-180810-1130

[5] Lampe, C., Ellison, N. and Steinfield, C. A. (2006). "Face (book) in the Crowd: Social Searching vs. Social Browsing.," in In proceedings of ACM Special Interest Group on Computer-Supported Cooperative Work (p. 167 e 170). ACM Pres. https://doi.org/ $\underline{10.1145 / 1180875.1180901}$

[6] Madhi, A. (2019). "Undergraduate students' perceptions towards social media usage and academic performance: A study from Saudi Arabia.," International Journal of Emerging Technologies in Learning, vol. 14(3), pp. 61-71. https://doi.org/10.3991/ijet.v14i03.9340

[7] Lenhart, A. (2007). "Cyberbullying. Washington, DC: Pew Research Center," www.pewinternet.org/Reports/2007/ Cyberbullying.aspx.

[8] Hinduja S., Patchin, J. (2006). "Bullies Move beyond the Schoolyard: A Preliminary Look at Cyberbullying.," Youth Violence and Juvenile Justice, vol. 4(2), pp. 148-169. https://doi.org/10.1177/1541204006286288

[9] O'Keeffe, G.S. \& Clarke-Pearson, K. (2011). "The Impact of Social Media on Children, Adolescents, and Families.," Pediatrics, 28, 127.

[10] American Psychological Association (APA). (2011). "Social networking's good and bad impacts on kids.," [Online]. Available: Retrieved from Science Daily: http://www. sciencedaily.com/releases/2011/08/110806203538.htm .

[11] Rideout, V. (2012). "Children, Teens, and Entertainment Media: The View from the Classroom.," A National Survey of Teachers about the Role of Entertainment, Media in Students' Academic and Social Development. 
[12] Abbas, J., Jaffar A., Nurunnabi, M. (2019). "The Impact of Social Media on Learning Behavior for Sustainable Education: Evidence of Students from Selected Universities in Pakistan.," Sustainability , vol. 11(6) , no. https://doi.org/10.3390/su11061683.

[13] Fernández-Antelo, I., Cuadrado-Gordillo, I., Parra, G. (2020). "Determining Factors in the Perception of Cyberbullying in Victimized Adolescents: Psychoeducational Implications," International Journal of Emerging Technologies in Learning, Vols. Vol. 15, No. 24, pp. 38-51. https://doi.org/10.3991/ijet.v15i24.19309

[14] Kim, H. (2017). "The impact of online social networking on adolescent psychological well-being (WB): a population-level analysis of Korean school-aged children.," International Journal of Adolescence and Youth, Volume 22(3), , pp. 364-376. https://doi. org/10.1080/02673843.2016.1197135

[15] Hamzi, A., Echantoufi, N., Khouna, J., Ajana, L. (2021). "Effects of Using Digital Tools on the Process of Memorization," International Journal of Emerging Technologies in Learning, Vols. Vol 16, No 04, pp. 278-295. https://doi.org/10.3991/ijet.v16i04.18285

[16] Livingstone, Sonia and Haddon, Leslie and Görzig, Anke and Ólafsson, Kjartan. (2011). Risks and safety on the internet: the perspective of European children: full findings and policy implications from the EU Kids Online survey of 9-16 year olds and their parents in 25 countries., London, UK: EU kids online, Deliverable D4. EU kids Online Network. https://doi.org/10.4135/978144627305014533936

[17] EU Kids Online. (2014) EU Kids Online: findings, methods, recommendations (deliverable D1.6)., London, UK: EU Kids Online, LSE. https://doi.org/10.2307/j.ctt 9qgvds.27

[18] Qirjako, G., Burazeri, G., Mihali, E., Bukli, M., Agolli, E. (2014). Sjelljet e shëndetshme tek fëmijët e moshës shkollore 11, 13 dhe 15 vjeç., http://ishp.gov.al/multimedia/ botime/libri_hbsc.pdf: Instituti i Shendetit Publik me mbeshtetje te UNFPA, UNICEF.

[19] Currie, C. (2012). "Social determinants of health and well-being among young people. Health Behaviour in School-aged Children (HBSC) study: international report from the 2009/2010 survey.," WHO Regional Office for Europe, Health Policy for Children and Adolescent, No.6, Copenhagen. https://doi.org/10.1016/j.jadohealth.2020.03.024

[20] Davila J, Stroud CB, Starr LR. (2009). "Romantic and sexual activities, parent-adolescent stress, and depressive symptoms among early adolescent girls," J Adolescent. 32(4), p. 909 -924. https://doi.org/10.1016/j.adolescence.2008.10.004

[21] World Vision Albania \& Kosovo. (2014). "Child well-being.," Summary Report https://www.wvi.org/sites/default/files/WVA\&K\%20Child\%20Wellbeing\%20Summary\%20Report\%2006.08.2016.pdf.

\section{Authors}

Elda Tartari is a lecturer of the Aleksander Moisiu University of Durrës, Faculty of Education and she is a part time lecturer at the Department of Pedagogy and Psychology at the Tirana University. She has authored and co-authored many publications in peer reviewed journals at regional, national and international conferences and workshops. Email: eldatartari@gmail.com

Lindita Lutaj is a lecturer in the Aleksander Moisiu University of Durrës, Faculty of Education. She is working also as a part time pedagogue in the University of Tirana. She is author and co-authored of different scientific researches in education field and she is collaborator in various international projects. Email: 1.lutaj@yahoo.com

Article submitted 2020-12-28. Resubmitted 2021-03-01. Final acceptance 2021-03-01. Final version published as submitted by the authors. 